\title{
Reconstrução do membro inferior com retalho fasciocutâneo de pedículo distal - Técnica de Monteiro modificada, série de 15 casos*
}

\section{Reconstruction of the Lower Limb with Fasciocutaneous Flap of the Distal Pedicle - Modified Technique of Monteiro, Series of 15 Cases* $^{*}$}

\author{
Saulo Souto Montenegro ${ }^{10}$ Antônio Carlos Costa ${ }^{2}$ Robert Meves ${ }^{2}$ R \\ 1 Serviço de Cirurgia Plástica, Hospital Universitário Lauro Wanderley,
Universidade Federal da Paraíba (UFPB), João Pessoa, PB, Brasil \\ Endereço para correspondência Saulo Souto Montenegro, MD, \\ ${ }^{2}$ Departamento de Ortopedia e Traumatologia da Faculdade de \\ Serviço de Cirurgia Plástica, Universidade Federal da Paraíba Centro \\ Ciências Médicas da Santa Casa de São Paulo, São Paulo, SP, Brasil \\ de Ciências da Saúde, Medicina, João Pessoa, PB, 58033-455, Brasil \\ (e-mail: saulosoutomontenegro@gmail.com).
}

Rev Bras Ortop 2020;55(6):736-741.

\section{Resumo \\ Palavras-chave \\ - retalhos cirúrgicos \\ - reconstrução \\ - extremidade inferior \\ - fáscia}

Objetivo Descrever e demonstrar o desfecho da técnica modificada de Monteiro (1991) para a reconstrução do membro inferior com retalho fasciocutâneo de pedículo distal numa série de 15 casos.

Método Com uma série de 15 casos, apresentamos a técnica e o desfecho da técnica modificada do retalho fasciocutâneo de pedículo distal com para a reparação do terço inferior da perna e do pé.

Resultados Os resultados foram satisfatórios porque os retalhos proporcionaram boa cobertura de pele e tecido celular subcutâneo nos casos de exposição óssea e perda cutânea. A área doadora foi fechada 3 dias após a cirurgia, com enxerto de pele de espessura parcial, proporcionando uma melhor viabilidade do enxerto.

Conclusão O retalho fasciocutâneo de pedículo distal mostrou-se como uma boa opção para a reconstrução do terço médio e inferior da perna, oferecendo boa cobertura óssea.

Objective To describe and demonstrate the outcomes of the modified Monteiro (1991) technique for lower limb reconstruction with a fasciocutaneous flap of the distal pedicle in a series of 15 cases.

Method We present the technique and outcomes from a series of 15 cases of the modified technique using a fasciocutaneous flap of the distal pedicle to repair the lower third of the leg and the foot.

\section{Keywords}

- surgical flaps

- reconstruction

- lower limb

- fascia
Results Outcomes were satisfactory since these flaps provided good cutaneous and subcutaneous tissue coverage in cases with bone exposure and skin loss. The donor area was closed 3 days after surgery with a partial skin graft to provide better graft viability. Conclusion The fasciocutaneous flap of the distal pedicle proved to be a good option for reconstruction of the middle and lower thirds of the leg, offering good bone coverage.

\footnotetext{
* Trabalho realizado no Hospital Universitário Lauro Wanderley (HULW-PB), da Universidade Federal da Paraíba (UFPB), João Pessoa, PB, Brasil.
}

recebido

15 de Agosto de 2019 aceito

02 de Março de 2020
DOI https://doi.org/

$10.1055 / \mathrm{s}-0040-1712494$. ISSN $0102-3616$.
Copyright $(2020$ by Sociedade Brasileira License terms de Ortopedia e Traumatologia. Published by Thieme Revinter Publicações Ltda, Rio de Janeiro, Brazil 


\section{Introdução}

A reconstrução de lesões complexas dos membros inferiores que, em muitas vezes, estão relacionados com uma grande perda tecidual com exposição e fratura de estrutura óssea é um procedimento frequente em razão do aumento da incidência do trauma na sociedade. ${ }^{1}$ A cobertura dessas lesões representa um desafio para o cirurgião, pois este deve ser capaz de efetivar tratamento integral da lesão, nos seus múltiplos aspectos, que inclui, além de sua reparação, a gestão de complicações que possam surgir durante e após a conduta adotada, sendo estas geralmente de difícil manejo. ${ }^{2}$

Complicações como o desenvolvimento de trombose venosa profunda, estase venosa e edema crônico, ocorrência frequente aterosclerose, dificuldade na regeneração nervosa, e necrose local de pele e músculos podem ocorrer na reparação de lesões graves. ${ }^{3}$

Segundo Ger, ${ }^{4}$ o tratamento de fraturas tibiais complexas mostra que a incorporação de músculo na pele aumenta seu suprimento sanguíneo. Pontén ${ }^{5}$ descreve o conceito de que a preservação da fáscia poderia aumentar a segurança dos retalhos cutâneos.

Retalhos microcirúrgicos são os mais indicados para a reparação das lesões situadas no terço distal da perna e no pé, mas essa técnica mais complexa é de difícil logística de realização em centros com menos recursos institucionais. ${ }^{6}$

As indicações e limites dos retalhos fasciocutâneos foram descritos em 1982. ${ }^{7}$ Existem retalhos com pedículo proximal que são mais indicados para a reparação nos dois terços proximais da perna. Basicamente, as técnicas para reconstrução de tecidos moles do membro inferior vão do uso de enxertos cutâneos, retalhos musculares, retalhos fasciocutâneos, e cross-leg até retalhos microcirúrgicos. Vários autores descreveram um retalho fasciocutâneo com pedículo distal para reparação de lesões no terço distal da perna e no pé. ${ }^{1,8-10}$

Atualmente, descreve-se retalhos fasciocutâneos que incluem a pele, tecido celular subcutâneo e fáscia, se baseando no sistema de vasos sanguíneos septocutâneos, os quais emergem através da intercomunicação com septos fasciais, se ramificando para formar plexos que suprem o tecido adiposo e a pele da região. ${ }^{11,12}$

A primeira opção para a reconstrução de partes moles do membro inferior deve ser pelo uso de retalhos fasciocutâneos, porque eles proporcionam uma cobertura cutânea resistente, e com aparência mais próxima do normal por se tratarem de retalhos regionais. Eles são de relativamente fácil execução, com grande versatilidade, e baseados em um padrão de anatomia vascular bem definido. Esses retalhos são usados mesmo em pacientes com insuficiência vascular associada, tais como diabetes mellitus e insuficiência venosa. ${ }^{13}$ Terziu e Djordjeviü ${ }^{14}$ afirmaram que suas características se sobressaem em relação a outros tipos de retalhos, especialmente por ter padrão de vascularização bem definido.

O terço distal da perna e o pé, entretanto, permanecem como áreas de difícil reparação, pois existem limitações em relação aos pedículos dos retalhos miocutâneos e fasciocutâneos. ${ }^{15}$

Tendo em vista o exposto, pretendemos apresentar uma série de 15 casos utilizando a técnica modificada do retalho fasciocutâneo de pedículo distal, tendo-se variado a angulação do retalho atingindo um maior eixo de rotação para reconstrução dos terços médio e distal do membro inferior, técnica esta que facilita o manejo do retalho na comparação com a técnica de Monteiro, descrita em $1991 .^{9}$

Descrever e demonstrar o desfecho da técnica modificada de Monteiro Júnior et al., ${ }^{9}$ 1991, para a reconstrução do membro inferior com retalho fasciocutâneo de pedículo distal numa série de 15 casos.

\section{Método}

O projeto foi enviado ao Comitê de Ética em Pesquisa com Seres Humanos, sob o número CAAE: 74112317.4.0000.5183.

Antes do experimento, cada voluntário foi informado sobre o objetivo do estudo e assinou o Termo de Consentimento Livre e Esclarecido (TCLE) de acordo com a Resolução 466/12 da Comissão Nacional de Ética em Pesquisa (CONEP).

Participaram do estudo indivíduos encaminhados ao serviço de cirurgia do Hospital Universitário Lauro Wanderlei (HULW) a fim de reparar lesões complexas do membro inferior, que atenderam aos seguintes critérios de inclusão:

- Apresentar lesão no membro inferior;

- Apresentar fratura óssea exposta ou não;

- Pacientes com idade superior a 18 anos;

- Não ter qualquer outra comorbidade que impeça a aplicação da técnica proposta no presente estudo.

- Pacientes com condição clínica favorável ao procedimento.

- Seguimento mínimo de 6 meses.

Inicialmente, foi realizado estudo das bases anatômicas para a confecção do retalho através da dissecção de cadáveres em decúbito ventral procedendo-se uma incisão transversa na face posterior da perna, mais ou menos a $6 \mathrm{~cm}$ da prega poplítea, incluindo pele, subcutâneo, e fáscia muscular. Duas outras incisões paralelas foram realizadas incluindo a fáscia, levantando desta forma o retalho com pedículo distal. Foi verificada a ocorrência das perfurantes identificadas no estudo original.

O trabalho foi realizado em pacientes com trauma do membro inferior, os quais foram submetidos a cobertura com retalho fasciocutâneo com pedículo distal. Todos os procedimentos ortopédicos foram feitos previamente ou concomitante à confecção do retalho.

Foi usada a anestesia peridural em L3-L4 com agulha de Touhy $\mathrm{n}^{\circ} 17$, injetando Novabupi (Itapira, São Paulo, Brasil) 0,5\%, $20 \mathrm{ml}$ associado a Fentanil (Itapira, São Paulo, Brasil) $100 \mathrm{mcg}$ para todos os pacientes. A técnica de dissecção e levantamento do retalho foi realizada em decúbito dorsal ou lateral conforme a lesão apresentada.

A confecção do retalho foi realizada na região distal da perna, seguiu uma linha proximal a 6 centímetros da fossa poplítea, e outras duas perpendiculares a ela, em sentido distal, parando a 12 centímetros do maléolo lateral e a 10 centímetros do maléolo medial. Esses pontos foram unidos, dando ao retalho a forma de 'raqueta', com base distal mais estreita que sua extremidade proximal, ficando o retalho com uma boa quantidade de tecido para cobertura das lesões do terço inferior da perna. 


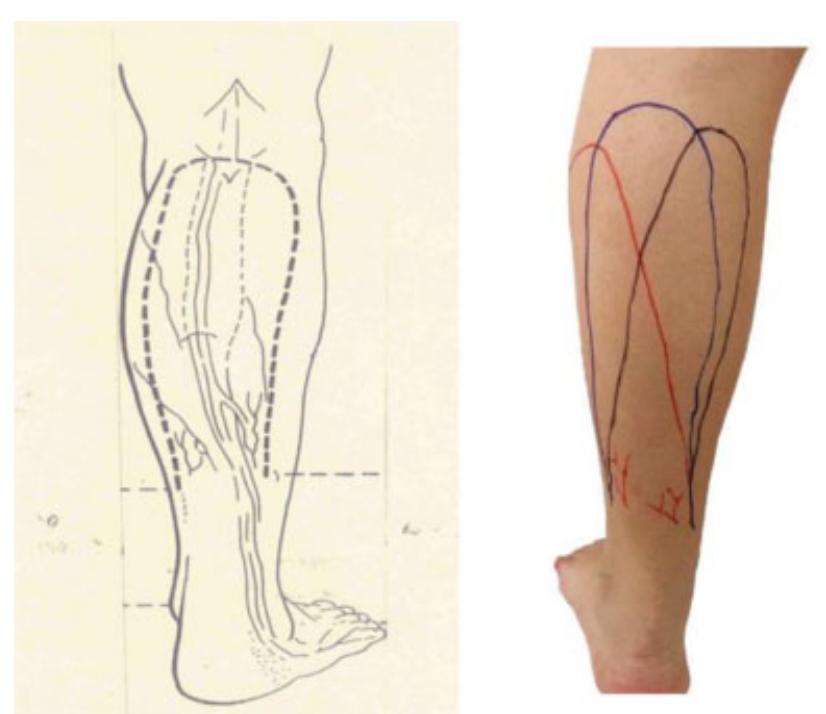

Fig. 1 Técnica original (no desenho) de dissecção e modificação (na foto) da angulação do retalho. O desenho do retalho original está indicado em azul, e, em preto e vermelho, está indicada a variação da angulação do retalho. Fonte: Monteiro Jr. et al., 1991, e dados da pesquisa, 2019.

A dissecação foi realizada em sentido craniocaudal, incluindo todos os planos, exceto o muscular. Os vasos perfurantes que emergem a partir do septo muscular foram cuidadosamente dissecados com trauma mínimo para os vasos. Os vasos perfurantes maiores laterais foram preservados. Dessa forma, o retalho foi então rodado e suturado em posição na área receptora previamente preparada. Foi feita a modificação na angulação do retalho, de acordo com o posicionamento da área do defeito, possibilitando assim, um maior arco de rotação e, consequentemente, uma melhor cobertura das lesões mais distais na reconstrução do membro inferior ( - Figura 1). As perfurantes musculares menores foram ligadas bem como o nervo sural e a veia safena externa. As perfurantes maiores lateral e medial foram isoladas.

A área doadora foi fechada com enxerto de pele de espessura parcial após 3 dias, quando o tecido de granulação foi formado, proporcionando uma melhor viabilidade desse enxerto. Após 3 semanas, o pedículo vascular foi ligado.

\section{Resultados}

Na série de casos apresentada, foram atendidos 15 pacientes com feridas complexas geradas por trauma nos membros inferiores. $O$ acompanhamento mínimo foi de 6 meses, esse é o período aproximando para que ocorra a integração do retalho, e o acompanhamento máximo foi de 24 meses, totalizando uma média de 8 meses de assistência, com desvio padrão de 4,89 . A média de idade foi de 39,38 anos, variando de 18 a 62 anos, com predominância dos pacientes na faixa etária de 25 a 29 anos. Houve um predomínio do sexo masculino, com 14 pacientes, e apenas 1 paciente do sexo feminino.

Foram considerados 13 casos com resultado excelente, pois apresentaram $100 \%$ de cobertura da pele e do tecido celular subcutâneo, presença de perfusão do retalho sem a
Tabela 1 Classificação de Gustilo e Anderson das fraturas expostas

\begin{tabular}{|l|l|}
\hline Tipo & Descrição \\
\hline I & Ferida $<\mathbf{1} \mathrm{cm}$ com mínima lesão de partes moles \\
\hline II & Ferida $>\mathbf{1} \mathrm{cm}$ com moderada lesão de partes moles \\
\hline III A & $\begin{array}{l}\text { Extensa laceração de partes moles ou retalhos com } \\
\text { cobertura de pele íntegra sobre osso fraturado, } \\
\text { ou trauma de grande energia independentemente } \\
\text { do tamanho da lesão }\end{array}$ \\
\hline III B & $\begin{array}{l}\text { Extensa lesão de partes moles com desnudamento } \\
\text { periosteal e exposição óssea, usualmente } \\
\text { associada a extensa contaminação }\end{array}$ \\
\hline III C & Fratura exposta com lesão arterial requerendo reparo \\
\hline
\end{tabular}

Fonte: Gustilo RB; Anderson JT, 1976.

presença de necrose, e ausência de infecção. Huve ainda um caso bom com a cobertura parcial de pele e tecido celular subcutâneo sobre a área do trauma com um seroma drenado sem prejuízo para o retalho, e um caso intermediário, pois apresentou perda ou necrose parcial do retalho (menor do que $5 \%$ ) sem exposição de qualquer estrutura abaixo do subcutâneo. Esses resultados foram classificados conforme os critérios de Odom modificados pelo autor. ${ }^{16}$

Os pacientes apresentaram fraturas expostas dos tipos III A e III B, de acordo com a classificação de Gustilo e Anderson ${ }^{17}$ lesão de partes moles do terço médio e inferior da perna (-Tabela 1, - Tabela 2). O retalho proporcionou boa cobertura de pele e tecido celular subcutâneo para os ossos expostos na série de 15 casos (-Figuras 2-10).

0 retalho teve as sequelas inerentes aos retalhos fasciocutâneos: cicatriz inestética na região doadora e hipoestesia na região lateral da perna e do pé. Não foram reportadas queixas, fato este que pode ser atribuído ao esclarecimento prévio dos pacientes quanto às "sequelas" produzidas pelo retalho. A área doadora, após evolução de 6 meses, ficou conforme a — Figura 6 e não comprometendo a função da perna.

\section{Discussão}

A presente série de casos mostrou que retalhos fasciocutâneos amplos podem ser levantados e rodados com poucas complicações. As desvantagens do uso dos retalhos fasciocutânetos do pedículo distal relacionam-se com a grande área doadora na perna que precisa ser enxertada, bem como com o procedimento ser realizado em dois tempos.

Uma reconstrução utilizando retalhos livres exige uma longa e onerosa hospitalização, treinamento cirúrgico muito especializado, e experiência bem como material de alto custo e longo tempo operatório, sendo estas as principais desvantagens desse método. ${ }^{13,15}$

O terço médio e distal da perna apresenta-se como local de difícil reparação quando temos exposição óssea e perda cutânea. Os retalhos microcirúrgicos exigem centros adequadamente aparelhados, equipe especializada, bem como altos custos institucionais. 
Tabela 2 Descrição dos casos com idade, etiologia da lesão, localização do defeito, fratura óssea e complicações

\begin{tabular}{|l|l|l|l|l|l|}
\hline Caso & Idade (anos) & Etiologia & Localização do defeito & Fratura exposta & Complicação \\
\hline 1 & 20 & Acidente de carro & Terço médio (perna) & III A & Seroma \\
\hline 2 & 16 & Acidente de carro & Terço médio (perna) & III A & Não \\
\hline 3 & 28 & Acidente de motocicleta & Terço médio (perna) & III A & Não \\
\hline 4 & 32 & Acidente de motocicleta & Terço médio (perna) & III A & Necrose parcial \\
\hline 5 & 42 & Acidente de carro & Terço médio (perna) & III B & Não \\
\hline 6 & 58 & Acidente de motocicleta & Terço médio (perna) & III B & Não \\
\hline 7 & 62 & Acidente de motocicleta & Terço distal (perna) & III B & Não \\
\hline 8 & 25 & Acidente de motocicleta & Terço distal (perna) & III B & Não \\
\hline 9 & 28 & Acidente de motocicleta & Terço distal (perna) & III B & Não \\
\hline 10 & 31 & Acidente de motocicleta & Terço distal (perna) & III B & Não \\
\hline 11 & 34 & Acidente de motocicleta & Terço distal (perna) & III B & Não \\
\hline 12 & 45 & Acidente de motocicleta & Terço distal (perna) & III B & Não \\
\hline 13 & 51 & Acidente de motocicleta & Terço distal (perna) & III B & Não \\
\hline 14 & 56 & Acidente de motocicleta & Terço distal (perna) & III B & Não \\
\hline 15 & 15 & Acidente de motocicleta & Terço distal (perna) & III B & Não \\
\hline
\end{tabular}

Fonte: Dados da pesquisa, 2019.

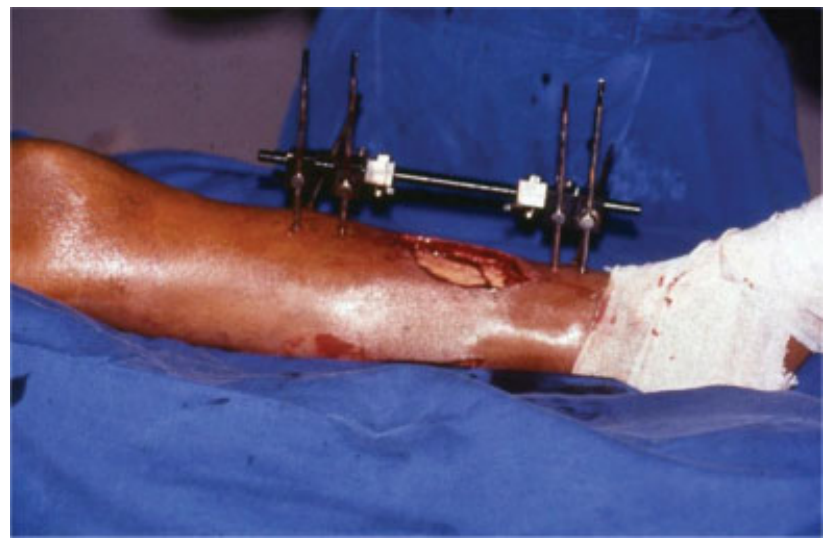

Fig. 2 Pré-operatório. Fonte: Dados da pesquisa, 2019.

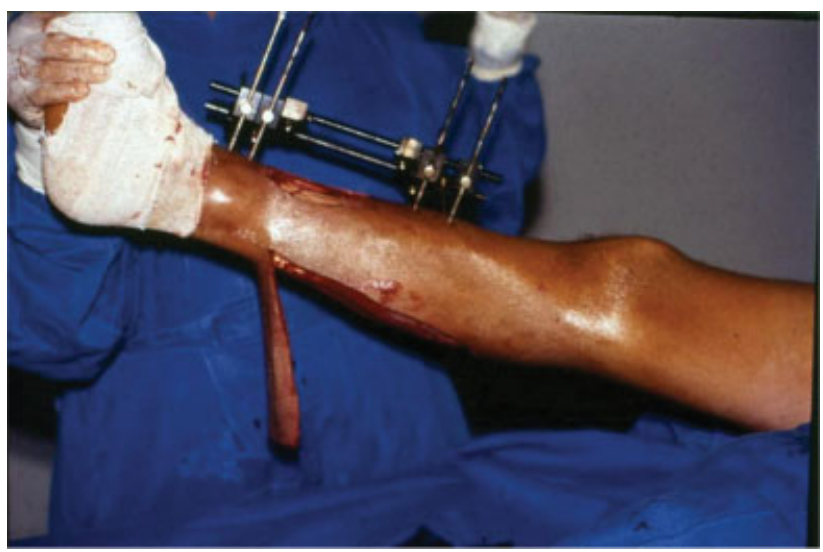

Fig. 3 Trans-operatório. Fonte: Dados da pesquisa, 2019.

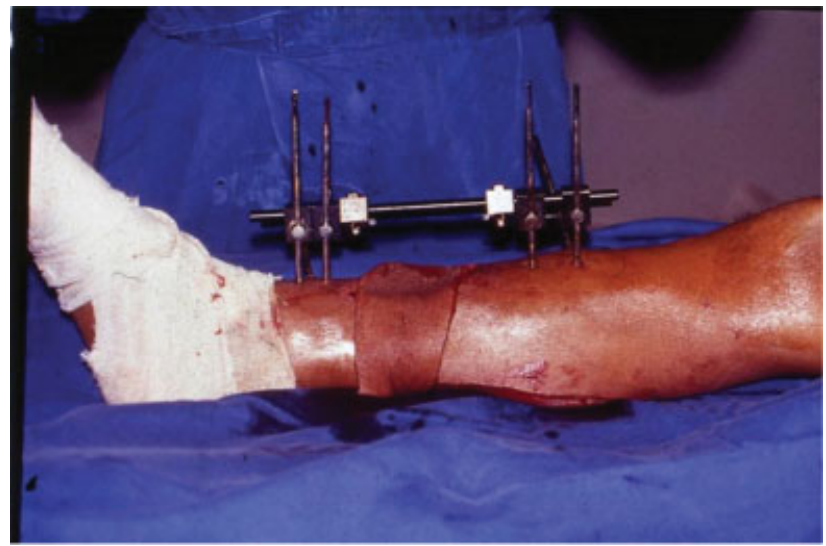

Fig. 4 Trans-operatório. Fonte: Dados da pesquisa, 2019.

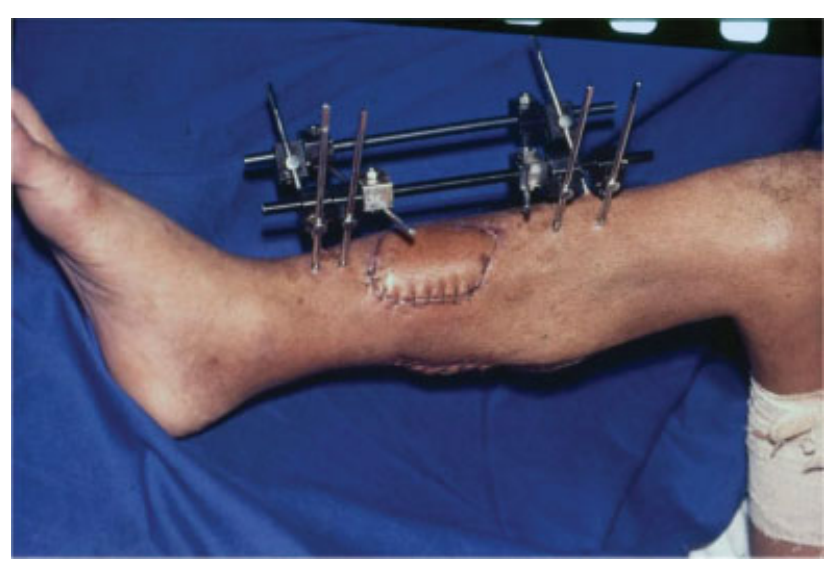

Fig. 5 Pós-operatório. Fonte: Dados da pesquisa, 2019. 


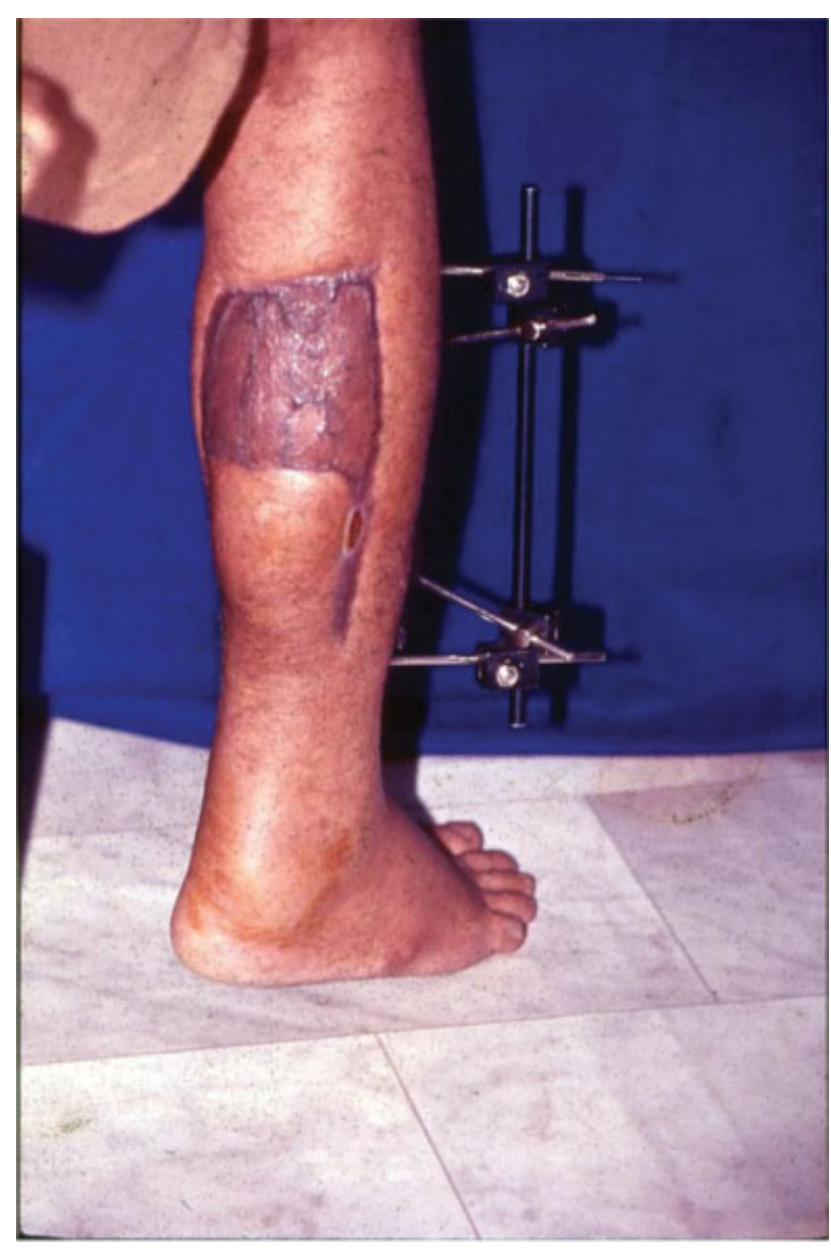

Fig. 6 Pós-operatório. Fonte: Dados da pesquisa, 2019.

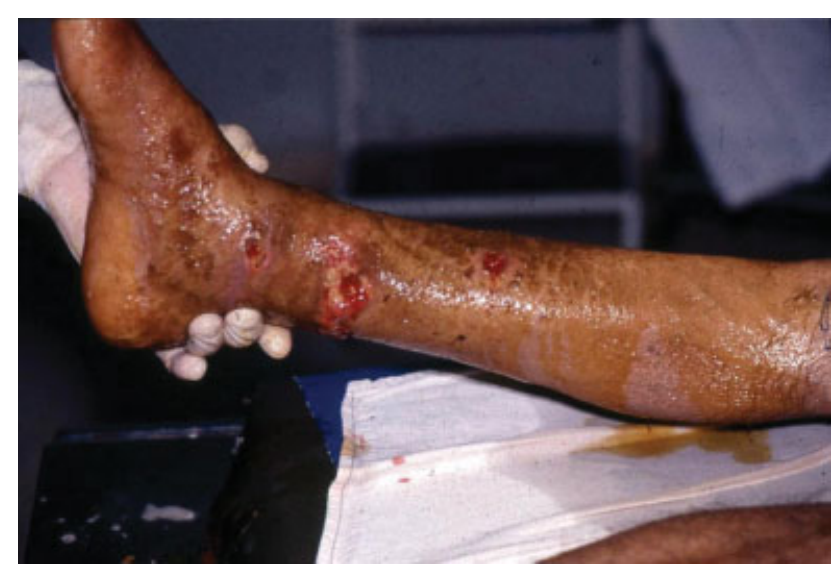

Fig. 7 Pré-operatório. Fonte: Dados da pesquisa, 2019.

Donski e Fogdestam, ${ }^{8}$ em 1983, transferiam seus retalhos baseados somente na perfurante lateral, enquanto os de Amarante et al., ${ }^{18}$ em 1986, eram baseados na perfurante medial. Esses retalhos eram menos seguros e poderiam ser comprometidos com a restrição do suprimento sanguíneo.

Em 1991, Monteiro Junior et al. ${ }^{9}$ adicionaram os dois pedículos mencionados na - Figura 1, aumentando em muito a segurança desses retalhos. Na nossa modificação, variando a angulação no desenho do retalho, aumentamos o arco de

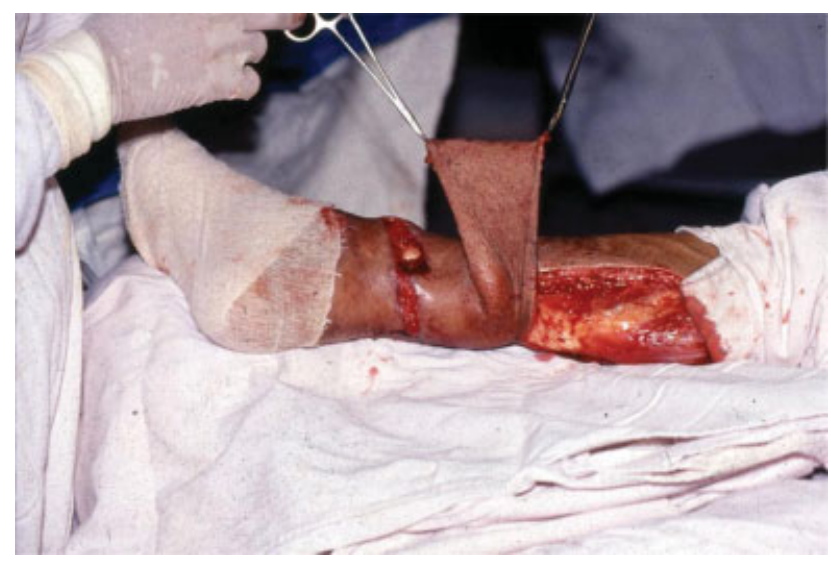

Fig. 8 Trans-operatório. Fonte: Dados da Pesquisa, 2019.

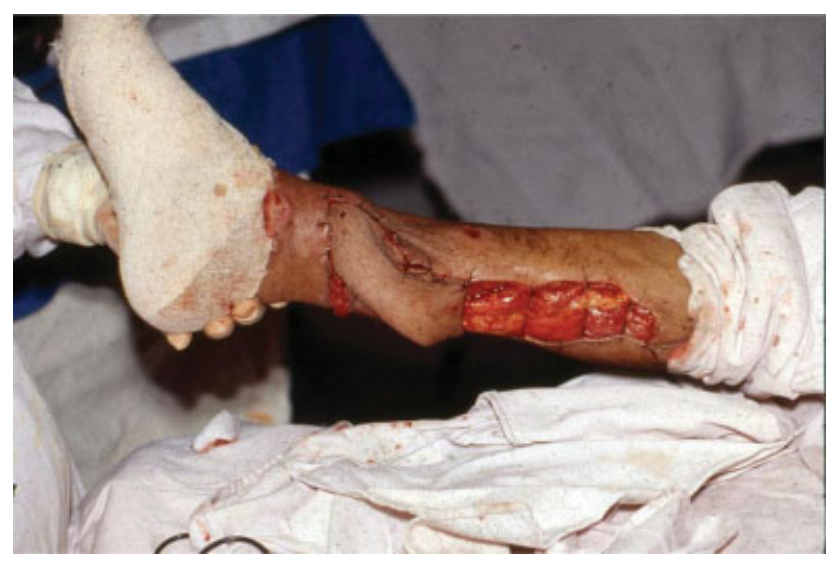

Fig. 9 Trans-operatório. Fonte: Dados da pesquisa, 2019.

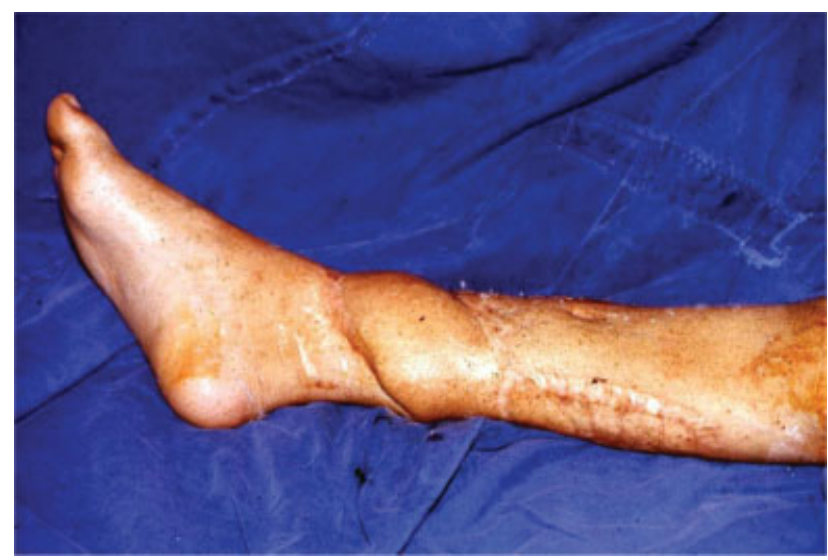

Fig. 10 Pós-operatório. Fonte: Dados da pesquisa, 2019.

rotação do mesmo sem prejuízo ao seu suprimento sanguíneo, fazendo com que se atinjam áreas mais distais da perna e do pé.

Como desvantagens, podemos citar a necessidade de dois tempos cirúrgicos para obtenção do resultado final, e as sequelas aparentes nas áreas doadoras dos retalhos.

Esse procedimento cirúrgico trouxe como benefícios para o paciente: ter seu membro recuperado, com retorno dos movimentos, dependendo do tipo de ferimento; ter sua imagem corporal restabelecida, elevando sua autoestima. 0 
procedimento trouxe ainda benefícios também para a instituição, uma vez que os resultados dessas cirurgias serão úteis no ensino de outros profissionais.

\section{Conclusão}

O retalho fasciocutâneo de pedículo distal confeccionado de acordo com a nossa modificação na angulação do desenho do mesmo, mostrou-se como uma boa opção para a reconstrução dos terços médio e inferior da perna, oferecendo boa cobertura de pele e tecido celular subcutâneo para o osso exposto, podendo ser um procedimento realizado em hospitais de média complexidade.

Conflito de Interesses

Os autores declaram não haver conflito de interesses.

\section{Referências}

1 Ríos-Luna A, Villanueva-Martínez M, Fahandezh-Saddi H, Villanueva-Lopez F, del Cerro-Gutiérrez M. Versatility of the sural fasciocutaneous flap in coverage defects of the lower limb. Injury 2007;38(07):824-831

2 Baumeister SP, Spierer R, Erdmann D, Sweis R, Levin LS, Germann GK. A realistic complication analysis of 70 sural artery flaps in a multimorbid patient group. Plast Reconstr Surg 2003;112(01): 129-140, discussion 141-142

3 Rezende RBM, Macedo JLS, Rosa SC, Galli FS. Epidemiological profile and treatment of substance losses by trauma to the lower limbs. Rev Col Bras Cir 2017;44(05):444-451

4 Ger R. The management of open fracture of the tibia with skin loss. J Trauma 1970;10(02):112-121

5 Pontén B. The fasciocutaneous flap: its use in soft tissue defects of the lower leg. Br J Plast Surg 1981;34(02):215-220
6 Ferreira MC, Besteiro JM, Monteiro Júnior AA, Zumiotti A. Reconstruction of the foot with microvascular free flaps. Microsurgery 1994;15(01):33-36

7 Barclay TL, Cardoso E, Sharpe DT, Crockett DJ. Repair of lower leg injuries with fascio-cutaneous flaps. Br J Plast Surg 1982;35(02): 127-132

8 Donski PK, Fogdestam I. Distally based fasciocutaneous flap from the sural region. A preliminary report. Scand J Plast Reconstr Surg 1983;17(03):191-196

9 Monteiro Júnior AA, Alonso N. Repair of cutaneous losses on the leg and foot with the distally based fasciocutaneous flap. Rev Soc Bras Cir Plast 1991;6(1/2):33-40

10 Hallock GG. Utility of both muscle and fascia flaps in severe lower extremity trauma. J Trauma 2000;48(05):913-917

11 Coehn M. Mastery of Plastic and Reconstructive Surgery. Boston: Little \& Brown Co; 1994

12 Taylor GI, Corlett RJ, Dhar SC, Ashton MW. The anatomical (angiosome) and clinical territories of cutaneous perforating arteries: development of the concept and designing safe flaps. Plast Reconstr Surg 2011;127(04):1447-1459

13 Benito-Ruiz J, Yoon T, Guisantes-Pintos E, Monner J, Serra-Renom JM. Reconstruction of soft-tissue defects of the heel with local fasciocutaneous flaps. Ann Plast Surg 2004;52(04):380-384

14 Terzić Z, Djordjević B. Clinical aspects of reconstruction of the lower third of the leg with fasciocutaneous flap based on peroneal artery perforators. Vojnosanit Pregl 2014;71(01):39-45

15 Costa-Ferreira A, Reis J, Amarante J. Reconstruction of soft-tissue defects of the heel with local fasciocutaneous flaps. Ann Plast Surg 2005;54(05):580-581

16 Odom GL, Finney W, Woodhall B. Cervical disk lesions. J Am Med Assoc 1958;166(01):23-28

17 Gustilo RB, Anderson JT. Prevention of infection in the treatment of one thousand and twenty-five open fractures of long bones: retrospective and prospective analyses. J Bone Joint Surg Am 1976;58(04):453-458

18 Amarante J, Costa H, Reis J, Soares R. A new distally based fasciocutaneous flap of the leg. Br J Plast Surg 1986;39(03):338-340 